Ege Tıp Dergisi / Ege Journal of Medicine 2019;58(2):136-139

\title{
Nötrofil / lenfosit oranı kronik hepatit B hastalarında karaciğer fibrozisini saptamada kullanılabilir mi?
}

Can neutrophil / lymphocyte ratio be used as a predictor of the hepatic fibrosis in chronic hepatitis B patients

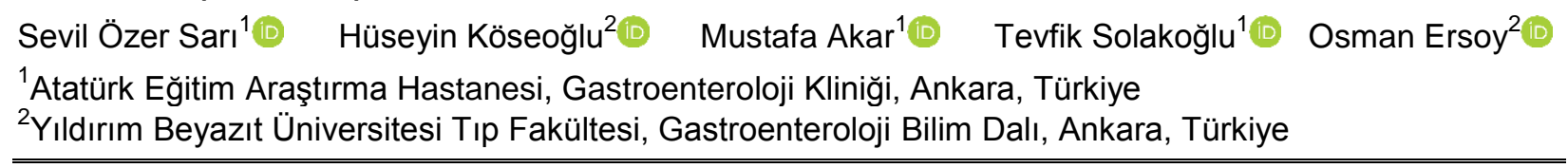

Öz

Amaç: Kronik hepatit B (KHB) hastalarında fibrozis değerlendirmesi siroz ve hepatosellüler kanser gelişimini önlemek açısından önemlidir. Karaciğer biyopsisi fibrozisi değerlendirmek için altın standarttır. Karaciğer biyopsisinin invaziv olması ve komplikasyonlarının olması nedeniyle karaciğer histopatolojisini gösterecek noninvaziv testler önem kazanmıştır. Nötrofil/lenfosit oranının (NLO) nonalkolik steatohepatitli ve KHB'li hastalarda fibrozis ile ilişkisini gösteren bazı çalışmalar bulunmaktadır. Bu çalışmanın amacı KHB'li hastalarda NLO ile karaciğer fibrozisi arasındaki ilişkiyi değerlendirmektir.

Gereç ve Yöntem: Hepatoloji polikliniğimizce takip edilen ve karaciğer biyopsisi olan 67 KHB'li hasta retrospektif olarak değerlendirildi. Tüm hastaların demografik verileri, laboratuvar parametreleri ve karaciğer biyopsisinde saptanan değerler kaydedildi.

Bulgular: Çalışmaya dahil edilen hastaların yaş ortalaması 48,6 $\pm 11,7$ yıl idi. 17 hasta kadın (\%25,4), 50 hasta erkekti (\%69,6). Fibrozis dereceleri 8 hastada 0, 15 hastada 1, 8 hastada 2, 18 hastada 3, 7 hastada 4, 9 hastada 5, 2 hastada 6 olarak değerlendirildi. KHB hastalarında karaciğer biyopsisinde saptanan fibrozis ile NLO arasındaki ilişkiye bakıldığında iki parametre arasında anlamlı bir ilişki saptanmadı $(p=0,54)$.

Sonuç: NLO oranı KHB'li hastalarda fibrozisi göstermede etkin bir parametre olarak görülmemiştir.

Anahtar Sözcükler: Kronik hepatit B, nötrofil/lenfosit oranı, fibrozis.

\begin{abstract}
Aim: Assessing fibrosis in chronic hepatitis B (CHB) patients is important in preventing cirrhosis and hepatocellular cancer development. Liver biopsy is the golden standard in evaluating fibrosis. Because liver biopsy is invasive and has complications, non-invasive tests to demonstrate liver histopathology have become more important. There are some studies that demonstrate the relationship between neutrophil/lymphocyte ratio (NLR) and fibrosis in nonalcoholic steatohepatitis and CHB patients. The purpose of the present study was to evaluate the relationship between NLR and hepatic fibrosis in CHB patients.
\end{abstract}

Materials and Methods: Sixty-seven patients who were under follow-up by our hepatology outpatient clinic and had liver biopsies were reviewed retrospectively. Demographics, laboratory parameters and values measured with liver biopsy were recorded for each patient.

Results: The mean age of the study population was $48.6 \pm 11.7$ years. Seventeen women (25.4\%) and 50 men (69.6\%) were included in the study. Fibrosis degree was 0 in 8 patients, 1 in 15, 2 in 8, 3 in 18, 4 in 7, 5 in 9, and 6 in 2. No significant relationship was found between fibrosis degree which was detected by liver biopsy and NLR in CHB patients $(p=0.54)$.

Conclusion: NLR ratio was not considered to be an effective parameter to demonstrate fibrosis in CHB patients.

Keywords: Chronic Hepatitis B, Neutrophil/Lymphocyte ratio, Fibrosis.

\footnotetext{
Yazışma Adresi: Sevil Özer Sarı

Atatürk Eğitim Araştırma Hastanesi, Gastroenteroloji Kliniği,

Ankara, Türkiye

E-mail: drsevilozer@yahoo.com

Makalenin Geliş Tarihi: 15.02.2018 Kabul Tarihi: 23.05.2018 


\section{Giriş}

Kronik Hepatit B (KHB) hastalarında erken evre fibrozisin siroza ve hepatosellüler kansere ilerleyişini durdurmak amaçlanmaktadır. Bu nedenle tedaviye erken dönemde başlanması önem kazanır. KHB hastalarında tedavi kararı genellikle serum HBV-DNA, alanin aminotransferaz (ALT) düzeyleri ve karaciğer biyopsisindeki nekroinflamasyonun derecesi ile fibrozisin evresine göre verilmektedir $(1,2)$. Karaciğer biyopsisi bugün halen fibrozisi ve hastalık aktivasyonunu değerlendirmek için altın standarttır (3). Karaciğer biyopsisinin kontrendikasyonlarının ve hayatı tehdit edebilecek komplikasyonlarının olması, hastanede yatış gerektirmesi, hatalı örnekleme yapılabilmesi intimali ve tekrar uygulanabilirliğinin zor olması hem hasta hem de klinisyen açısından kaygı verici olmaktadır (4-6). Bu nedenle karaciğer histopatolojisini gösterecek daha kolay, ucuz ve pratik testlerin geliştirilmesi önem kazanmıştır $(7,8)$. Nötrofil/lenfosit oranının (NLO) nonalkolik steatohepatitli (NASH) ve KHB'li hastalarda fibrozis ile ilişkisini gösteren bazı çalışmalar bulunmaktadır $(9,10)$. Alkhouri ve ark. (9) NASH'li hastalarda nekroinflamatuar aktivite ve fibrozis derecesi ile NLO arasında belirgin korelasyon saptanmıştır. Yeşil ve ark. (10) yaptığı çalışmada ise kronik HBV'li hastalarda NLO ile fibrozis arasında pozitif korelasyon tespit edilmiştir (10). Kronik HBV'li hastalarda karaciğer histopatolojisini gösterebileceği öne sürülen birçok laboratuvar ve görüntüleme yöntemi ile ilgili araştırmalar yapılmış olup bizim çalışmamızda amaç nötrofil/lenfosit oranının KHB'li hastalarda karaciğer fibrozisinin göstergesi olup olamayacağının araştırılmasıdır.

\section{Gereç ve Yöntem}

Çalışmamızda hepatoloji polikliniğimizce takip edilen 179 kronik hepatit B hastasının dosyası retrospektif olarak değerlendirildi. Bu hastalardan KHB'li karaciğer biyopsisi olan, daha öncesinde tedavi almamış, HBeAg negatif, alkol kullanımı olmayan, Anti HDV ve Anti HCV negatif, otoimmun ve metabolik karaciğer hastalıklarının eşlik etmediği, önceki takiplerinde karaciğer yağlanması saptanmayan, ek sistemik hastalığı olmayan, diğer sistem maligniteleri ve hepatosellüler karsinom (HCC) gelişimi saptanmayan, 67 hasta çalışmaya dahil edildi. Tüm hastaların demografik verileri, AST, ALT, protrombin zamanı (PT), albümin, NLO, HBV-DNA ve Knodell skoruna göre fibrozis ve histolojik aktivite indeksi (HAi) değerleri kaydedildi. Elde edilen veriler SPSS 20 programına kaydedildi ve hesaplamalar bu program üzerinde gerçekleştirildi. Verilerin normallik varsayımını sağlayıp sağlamadığının saptanması için öncelikle Kolmogorov-Smirnov testi yapıldı. Test sonucuna göre normallik varsayımını sağlayan değişkenler için parametrik bağımsız t-testi, sağlamayan değişkenler için ise non-parametrik Mann-Whitney $U$ testi uygulandı. Hastalar fibrozis değerlerine göre erken evre ve ileri evre fibrozis olarak 2 gruba ayrıldı ve fibrozis grupları ile diğer veriler Mann-Whitney $U$ testi ile karşılaştırıldı. $p<0.05$ değerleri istatistiksel olarak anlamlı kabul edildi.

\section{Bulgular}

Çalışmaya dahil edilen $67 \mathrm{HBeAg}$ negatif KHB hastasının yaş ortalaması $48,6 \pm 11,7$ yıl idi. 17 hasta kadın $(\% 25,4)$, 50 hasta erkekti $(\% 74,6)$. Hastalara ait demografik özellikler ve laboratuvar verileri Tablo-1'de gösterilmiştir. 8 hastanın fibrozis skoru $0 / 6(\% 11,9), 15$ hastanın $1 / 6$ (\%22,3), 8 hastanın $2 / 6(\% 11,9), 18$ hastanın $3 / 6(\% 26,9)$, 7 hastanın 4/6 (\%10,4), 9 hastanın 5/6 (\%13,5), 2 hastanın 6/6 (\%3) olarak saptandı (Tablo-2).

Tablo-1. Demografik Özellikler ve Laboratuvar Verileri.

\begin{tabular}{l|c}
\hline Yaş $^{*}$ & $48,6 \pm 11,7$ \\
\hline Cinsiyet (K/E) & $17(\% 25,4) / 50(\% 74,6)$ \\
\hline AST* $^{*}(0-32 \mathrm{U} / \mathrm{L})$ & $51,7 \pm 32,3$ \\
\hline ALT $^{*}(0-33 \mathrm{U} / \mathrm{L})$ & $84,3 \pm 69,5$ \\
\hline PT $^{*}(9.8-15.2 \mathrm{sn})$ & $12,7 \pm 1,1$ \\
\hline Albumin $^{*}(3.5-5.2 \mathrm{~g} / \mathrm{dL})$ & $4.20 \pm 0.45$ \\
\hline HBV-DNA $^{* *}(\mathrm{kopya} / \mathrm{mL})$ & $1,3 \times 10^{6}$ \\
\hline NLO & $2,48 \pm 1,24$ \\
\hline Fibrozis & $2,3 \pm 1,7$ \\
\hline HAi & $7,4 \pm 3,6$ \\
\hline
\end{tabular}

Normal dağılım gösterdiği için ortalama \pm standart sapma değeri alınmıştır.

"Normal dağııım göstermediği için ortanca değer alınmıştır.

Tablo-2. Fibrozis Düzeyi Hasta Sayısı

\begin{tabular}{c|c}
\hline Fibrozis & Hasta Sayısı \\
\hline F0 & 8 \\
\hline F1 & 15 \\
\hline F2 & 8 \\
\hline F3 & 18 \\
\hline F4 & 7 \\
\hline F5 & 9 \\
\hline F6 & 2 \\
\hline
\end{tabular}

Hastalar erken evre fibrozis (F0, 1, 2, 3) ve ileri evre fibrozis $(F 4,5,6)$ olarak 2 gruba ayrılarak değişkenler ile fibrozis grupları arasında karşılaştırmalar yapıldı. Bu karşılaştırmalar Tablo-3'te verilmiştir.

Tablo-3. Grup 1 ve Grup 2 Fibrozisle Değişkenler Arasındaki Karşılaştırma.

\begin{tabular}{lccc}
\hline & $\begin{array}{c}\text { Fibrozis Grup1 } \\
(0,1,2,3)(\mathrm{n}: 54)\end{array}$ & $\begin{array}{c}\text { Fibrozis Grup 2 } \\
(4,5,6)(\mathrm{n}: 13)\end{array}$ & $\mathrm{p}$ \\
\hline NLO & $2,176 \pm 0,7$ & $2,052 \pm 0,73$ & 0,547 \\
Trombosit & $213.574 \pm 73.089$ & $135.923 \pm 77.476$ & $\mathbf{0 , 0 0 1}$ \\
Albumin & $4,3 \pm 0,35$ & $3,8 \pm 0,59$ & $\mathbf{0 , 0 0 3}$ \\
AST & $50 \pm 32,2$ & $60 \pm 32,5$ & 0,168 \\
ALT & $87 \pm 74,6$ & $73 \pm 41,9$ & 0,893 \\
PT & $12,5 \pm 1,05$ & $13,5 \pm 1,22$ & $\mathbf{0 , 0 0 5}$ \\
HAI & $6,9 \pm 3,43$ & $9,5 \pm 3,57$ & $\mathbf{0 , 0 2 9}$ \\
YAŞ & $46 \pm 11,75$ & $54 \pm 9,05$ & $\mathbf{0 , 0 1 7}$ \\
HBV-DNA & $1,25 \times 10^{6}$ & $7,7 \times 10^{6}$ & 0,490 \\
& $\left(1,72 \times 10^{5}-1,30 \times 10^{7}\right)$ & $\left(3,15 \times 10^{5}-2 \times 10^{7}\right)$ & \\
\hline
\end{tabular}

*Normal dağılıma uymadığı için median değerler verilmiştir. 
Çalışmada değerlendirmeye alınan parametrelerin fibrozis ile korelasyonu yapıldığında; HAl değerleri ile fibrozis arasında pozitif yönde ( $p=0,029, \quad r=0,268)$, albümin ve trombosit değeri ile fibrozis arasında negatif yönde bir korelasyon tespit edildi $[(p=0,003 ; r=0,371)$, $(p=0,001) ;(r=0,427)]$. Ayrıca PT değerleri ile fibrozis arasında da $(p=0,005 ; r=0,347)$ olacak şekilde pozitif yönde korelasyon tespit edilirken, HBV DNA, ALT ve AST düzeyleri ile fibrozis arasında anlamlı bir korelasyon saptanmadı. Yaş ile fibrozis arasında da pozitif yönde korelasyon saptandı $(p=0,017 ; r=0,294)$. Cinsiyet ile fibrozis gelişimi açısından ise anlamlı bir ilişkiye rastlanmadı. KHB hastalarında karaciğer biyopsisinde saptanan fibrozis ile NLO arasındaki ilişkiye bakıldığında ise iki parametre arasında anlamlı bir ilişki saptanmadı $(p=0,54)$. HAI ile NLO arasında ise orta düzeyde anlamlı bir pozitif korelasyon saptandı $(r=0,249)$.

\section{Tartışma}

KHB'li hastalarda karaciğer fibrozisi ve HCC gibi komplikasyonların gelişimini önlemek için tedavi başlama endikasyonunun belirlenmesi son derece önemlidir. KHB'de tedavi kararı açısından öncelikle yapılması gereken değerlendirmeler ALT ve viral yükün belirlenmesidir. Hastada bu değerlendirmenin ardından tedaviye başlanabilmesi için karaciğer biyopsisi yapılması ya da hastanın laboratuvar değerleri ile takibi kararı alınır. Ancak bazen sirotik hastalarda ileri düzeydeki hücre hasarına bağlı olarak viral yük düşük olabilir. Bu nedenle viral yükün düşük saptanması karaciğer hasarı açısından bir belirteç olarak kullanılamamaktadır. Her hastada rutin olarak istenebilen, kolay elde edilebilir, basit ve pratik bir veri olması NLO'yu popüler bir belirteç haline getirmiştir. NLO ile ilgili yapılan bazı çalışmalarda NLO ile fibrozis arasında ilişki olduğu gösterilmiş ve NLO oranının noninvaziv ve ucuz bir fibrozis belirteci olabileceği ileri sürülmüştür $(10,11)$. Gong ve ark. (12) yaptığı bir çalışmada ise NLO'nun KHB'de hastalığın ciddiyetini ve mortalitesini göstermede önemli bir belirteç olduğu saptanmıştır. Aynı zamanda diğer bazı inflamatuvar hastalıklar ve malign hastalıklarda da hastalık aktivasyonu ve prognozunun belirleyicisi olarak NLO oranının kullanılabileceğine dair çalışmalar mevcuttur $(13,14)$. Yeşil ve ark. (10) yaptığı çalışmada fibrozis ile
NLO arasında ilişki saptanmış olsa da, çalışmamızda NLO oranı KHB'li hastalarda fibrozisi göstermede etkin bir parametre olarak görülmemiştir. Kronik hepatitli ve sirotik hastalarda inflamasyondan esas sorumlu hücreler lenfomononükleer hücrelerdir (15). Doku içinde yer alan mononükleer inflamasyonun NLO değeri ile değerlendirilmesi ortaya doğru ve güvenilir sonuçlar çıkarmayabilir. Bu nedenle de KHB'li hastalarda NLO oranının fibrozisi belirlemede etkin bir test olamayacağını düşündürmektedir. Kekilli ve ark. (16) KHB'de NLO fibrozis ilişkisinin değerlendirildiği çalışmada Yeşil ve ark. (10) yaptığı çalışmanın tersine fibrozis derecesi arttıkça NLO'nun azaldığı saptanmıştır. Literatürde KHB'de NLO-Fibrozis ilişkisi değerlendirildiğinde hem pozitif hem de negatif korelasyonların saptanmış olması, ayrıca bizim çalışmamızda da ilişki saptanmamış olması NLO'nun fibrozis göstergesi olarak kullanıımasının uygun olmadığını destekler niteliktedir

HAI değerleri ile fibrozis arasında pozitif yönde, albümin ve trombosit değeri ile fibrozis arasında negatif yönde, PT değerleri ile fibrozis arasında da pozitif yönde saptanan anlamlı korelasyonlar beklenen sonuçlardır. İleri evre fibrozisli olgularda AST değerlerinin erken evre fibrozisi olan hastalara göre daha yüksek olması beklenen bir bulgu iken çalışmamızda gruplar arasında fark saptanmamasının nedeni hastaların büyük oranda Fibrozis 1-4 arasında yoğunlaşması ile açıklanabilir.

Çalışmamızda NLO ile HAI arasında düşük düzeyde de olsa anlamlı bir pozitif korelasyon saptanmış olması çalışmaya dahil edilen hasta sayısının azlığı ve ileri fibrozisi olan hasta sayısının toplam hasta sayısına oranının düşük olmasına bağlı olarak NLO ve fibrozis arasında korelasyon saptanamadığını düşündürebilir. Ayrıca çalışmamızdaki diğer sınırlayıcı faktörler çalışmanın retrospektif ve tek merkezli olmasıdır. Daha büyük sayıdaki hasta popülasyonları ile çok merkezli, prospektif olarak yapılacak çalışmalar fibrozis ile NLO ilişkisi konusunda daha aydınlatıcı fikirler verebilir.

\section{Sonuç}

Çalışmamızın sonucunda NLO oranı KHB'li hastalarda karaciğer fibrozisini göstermede etkili bir belirteç olarak görülmemiştir.

\section{Kaynaklar}

1. Lok ASF, McMahon BJ. AASLD practice guideline: Chronic hepatitis B: Update of therapeutic guidelines. Rom J Gastroenterol 2004;13(2):150-4.

2. McMahon BJ. Epidemiology and natural history of hepatitis B. Semin Liver Dis 2005;25(Suppl 1):3-8.

3. Bravo A, Sheth SG, Chopra S. Liver biopsy. N Eng J Med 2001;344(7):495-500.

4. Mardini $\mathrm{H}$, Record $\mathrm{C}$. Detection of assessment and monitoring of hepatic fibrosis: Biochemistry or biopsy? Ann Clin Biochem 2005;42(Pt 6):441-7. 
5. Piccinino F, Sagnelli E, Pasquale G, Giusti G. Complications following percutaneous liver biopsy. A multicentre retrospective study on 68.276 biopsies. J Hepatol 1986;2(2):165-73.

6. Lee IC, Huang YH, Chan CC. Impact of body mass index and viral load on liver histology in hepatitis B e antigen-negative chronic hepatitis B. Clin Nutr 2011;30(5):647-52.

7. Ucar F, Sezer S, Ginis Z et al. APRI, the FIB-4 score, and Forns index have noninvasive diagnostic value for liver fibrosis in patient with chronic hepatitis B. Eur J Gastroenterol Hepatol 2013;25(9):1076-81.

8. Martinez SM, Crespo G, Navasa M, Forns X. Noninvasive assesment of liver fibrosis. Hepatology 2011;53(1):325-35.

9. Alkhouri N, Morris-Stiff G, Campbell C, et al. Neutrophil to lymphocyte ratio: New marker for predicting steatohepatitis and fibrosis in patient with nonalcoholic fatty liver disease. Liver Int 2012;32(2):297-302.

10. Yeşil A, Coşgun A, Erdem E, Koçhan K, Gündüz F, Gönen $C$. The relationship between fibrosis level and blood neutrophil to lymphocyte ratio in chronic HBV patient. Akademik Gastroenteroloji 2013;12(2):66-8.

11. Biyik M, Ucar R, Solak $Y$, et al. Blood neutrophil-to-lymphocyte ratio independently predicts survival in patients with liver cirrhosis. Eur J Gastroenterol Hepatol. 2013;25(4):435-41.

12. Gong J, Liang YL, Zhou W, et al. Prognostic value of neurophil to lymphocyte ratio associated with prognosis in HBV-infected patients. J Med Virol 2018;90(4):730-5.

13. Çelikbilek M, Dogan S, Ozbakır O, et al. Neutrophil-lymphocyte ratio as a predictor of disease severity in ulcerative colitis. J Clin Lab Anal 2013;27(1):72-6.

14. Guthrie GJ, Charles KA, Roxburgh CS, Horgan PG, McMillan DC, Clarke SJ. The systemic inflammation-based neutrophillymphocyte ratio: Experience in patients with cancer. Crit Rev Oncol Hematol 2013;88(1):218-30.

15. Calvaruso V, Craxi A. Fibrosis in chronic viral hepatitis. Best Pract Res Clin Gastroenterol 2011;25(2):219-30.

16. Kekilli M, Tanoglu A, Sakin YS, Kurt M, Ocal S, Bagci S. Is the neutrophil to lymphocyte ratio associated with liver fibrosis in patients with chronic hepatitis B? World J Gastroenterol 2015;21(18):5575-81. 